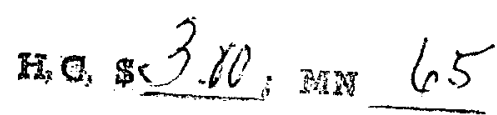

\title{
POTENTIAL APPLICATIONS FOR AN UNDER-SODIUM ULTRASONIC SCANNING DEVICE
}

\author{
AEC Contract No. AT (11-1)-865 \\ Project Agreement No. 14 \\ Division of Reactor Development and Technology \\ C. C. Scott \\ P. R. Huebotfer* \\ R. C. Callen
}

*Presently Associated with Argonne National Laboratory Argonne, Illinois

\section{LEGAL NOTICE}

Thie report was This report was prepared as an account of Government sponsored work. Neither

A. Makes any A. Makes any warranty or represterise

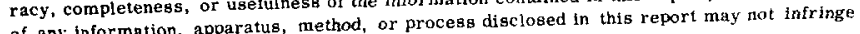
of any information, appars

privately owned rights; or with B. Assumes any liabillties with respect to the use of, or for dameses this report.

use of any information, apparas " includes any emAs used in the above, "pers ployee or contractor of the Commisen, such employee or contractor of the Conn information pursuant to his employment or contract disseminates, or provides acemployment with such contractor.

This document is PUBLICLY RELEASABLE Laver E Huthans

Date: $01 / 18 / 2007$ 


\section{DISCLAIMER}

This report was prepared as an account of work sponsored by an agency of the United States Government. Neither the United States Government nor any agency Thereof, nor any of their employees, makes any warranty, express or implied, or assumes any legal liability or responsibility for the accuracy, completeness, or usefulness of any information, apparatus, product, or process disclosed, or represents that its use would not infringe privately owned rights. Reference herein to any specific commercial product, process, or service by trade name, trademark, manufacturer, or otherwise does not necessarily constitute or imply its endorsement, recommendation, or favoring by the United States Government or any agency thereof. The views and opinions of authors expressed herein do not necessarily state or reflect those of the United States Government or any agency thereof. 


\section{DISCLAIMER}

Portions of this document may be illegible in electronic image products. Images are produced from the best available original document. 
Previous AEC-sponsored development work on various concepts of under-sodium scanning devices has resulted in the selection of a single approach, described herein, that represents the best compromise of simplicity, flexibility, range, and resolution. In the context of the capabilities and limitations of this approach, which employs a narrow-beam ultrasonic transducer with a metallic focusing lens operable in sodium at $600 \mathrm{~F}$, numerous applications in existing and future sodium-cooled reactors and associated research and development projects are possible. A survey of these applications has been made, evaluated, and reduced to a single demonstration objective which represents a common denominator of most of the applications of greatest potential interest in the Liquid Metal Fast Breeder Reactor (LMFBR) development program. This demonstration, which could be first pursued in an out-of-pile mock-up facility and then be followed by a demonstration in an existing sodium-cooled reactor, is defined in this report as the recommended near-term goal for a follow-on development effort. 
TABLE OF CONTENTS

$\underline{\text { Page }}$

LIST OF ILLUSTRA TIONS $\ldots \ldots \ldots \ldots \ldots \ldots \ldots \ldots \ldots \ldots \ldots \ldots \ldots$

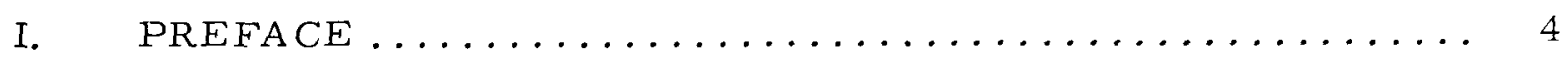

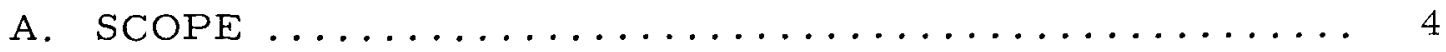

B. RELATIONSHIP TO OTHER PROJECTS ............. 4

II. INTRODUCTION $\ldots \ldots \ldots \ldots \ldots \ldots \ldots \ldots \ldots \ldots \ldots \ldots \ldots \ldots$

III. DEVELOPMENT OF THE DEVICE $\ldots \ldots \ldots \ldots \ldots \ldots \ldots$

IV. CAPABilities AND limitations of the device...... 19

V. SURVEY OF POTENTIAL APPLICATIONS

FOR THE DEVICE ........................ 25

VI. EVALUATION OF POTENTIAL APPLICATIONS

AND RECOMMENDATIONS FOR FUTURE WORK ......... 29

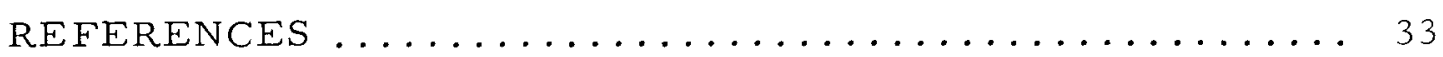

ACKNOWLEDGMENTS ....................... 34 


\section{LIST OF ILLUSTRATIONS}

Figure

$\underline{\text { Title }}$

$\underline{\text { Page }}$

1 Focusing Transducer with Metal Lens $\ldots \ldots \ldots \ldots \ldots$

2 Under-Sodium Ultrasonic Scanning Test Facility .......... 9

3 Ultrasonic Absorption in Liquid Sodium .............. 10

4 Intensity Attenuation in Liquid Sodium $\ldots \ldots \ldots \ldots \ldots \ldots \ldots$

5 Velocity of Sound in Liquid Sodium $\ldots \ldots \ldots \ldots \ldots \ldots \ldots \ldots \ldots$

6 A Typical Ray Path in Backing Layer ............... 14

7 Beam Width at Long Distance Depending on Radius of Curvature of Refraction Surface ................. 15

8 Narrow-Beam Transducer Return Signal from Tank Wall



9 Narrow-Beam Transducer Return Signal from Target Rod

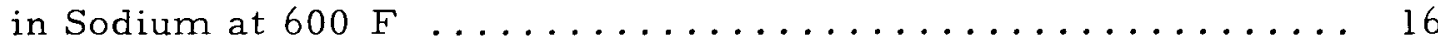

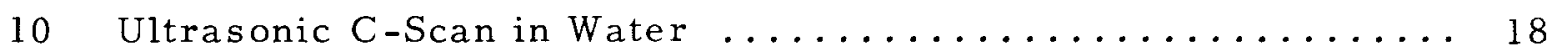

11 Half-Intensity Point from Acoustic Source in Liquid Sodium .... 20

12 Typical Signal Obtained from Transducers Operating in Liquid Sodium ........................ 22

13 Identification Marks on Subassemblies .............. 30 


\section{PREFACE}

\section{A. SCOPE}

The scope of the study reported herein was to:

- Select, from the under-sodium scanning concepts previously studied at APDA, the most promising approach whose technological status is such that potentially interesting applications can be cited with reasonable confidence.

- Describe, for purposes of an applications survey, the development, capabilities, and limitations of the above-selected scanning approach.

- Perform, with the assistance of personnel associated with the Fermi reactor, Experimental Breeder Reactor-II (EBR-II), Fast Flux Test Facility (FFTF), Sodium Reactor Experiment (SRE), and Hallam projects, an applications survey for an instrument with the abovestated capabilities and limitations.

- Evaluate the list of applications and select a single application on which to focus follow-on design, fabrication, installation, and test work.

\section{B. RELATIONSHIP TO OTHER PROJECTS}

An instrument which would permit objects in liquid sodium to be discerned by means of sound waves is potentially applicable to all reactor sys tems that use sodium as the primary coolant. In a general sense, such an instrument is visualized as a tool to simplify maintenance and fuel handling in an opaque liquid metal. The search for more specific identification of the instrument's value to existing and future reactors of this type is part of the present work scope. 


\section{INTRODUCTION}

Though sodium possesses advantageous properties as a coolant for nuclear reactors, especially when breeding is desired, its opacity is at times a handicap to maintenance and fuel handling operations. Economically competitive sodium-cooled fast breeder reactors must have high power densities and high plant factors. As a result, maintenance and fuel handling operations must generally be performed when the decay power is too high to permit draining of the sodium for visual monitoring of such operations. These facts provide the incentive for developing a general purpose undersodium ultrasonic scanning system to replace, to the greatest possible extent, the optical monitoring of submerged regions feasible in reactors using a transparent primary coolant. This development work has been pursued by APDA personnel since 1962 at various levels of intensity.

Progress on the development of several concepts of the general purpose ultrasonic scanning device has been documented in two topical reports 1,2 and more recently, in quarterly reports on $\mathrm{AEC}$-sponsored projects. $3,4,5,6,7$ As a result of theoretical calculations and experimentation in wate $r$ and sodium, sufficient background now exists to select one of the concepts studied as the most promising for further development as an under-sodium scanning device of wide potential applicability.

Electronic acoustic methods for transforming sound images into visible images on a television screen have been explored in the course of earlier work, but the complexities of the electronics have not been completely solved; however, since many of the potential applications of the acoustic image converter can be satisfied by an acoustic transmitter-receiver (sonar) system operated in the C-scan mode (line-by-line scanning), the latter is selected as the device whose applications can be cited, with reasonable confidence, on the basis of proven technology.

Of the several transducer designs evaluated experimentally at APDA, the focusing transducer with a metallic planospherical concave acoustic focus ing lens has demonstrated the best performance. In both water and $600 \mathrm{~F}$ sodium, the ultrasonic beam was found to remain in sharp focus beyond the focal point of the lens. This observation, which is contrary to the analogous situation in optics, eliminated the suspected need to use an acoustic collimator such as a transducer with conical-and wedge-shaped horns in series.

Two basic types of acoustic systems exist. In one, the transmitter (transducer) and receiver are separate units. When using this system, objects are examined by the acoustic shadows they cast when in the line of the acoustic beam. A second type of system, in which one transducer operates 
as both the transmitter and receiver, was chosen for these studies. Its primary advantage lies in ease of mechanical alignment. A diagram of the basic unit is shown in Fig. 1 .

Although line-by-line scanning is possible with the unitized concept, a more complete display of the image may be obtained with the transmitter and receiver as separate units. However, there are two formidable disadvantages to using the latter approach as a general purpose under-sodium scanner. They are as follows:

- The auxiliary mechanical equipment needed to move and orient the transducer into the desired spot in the reactor would have to be more than twice as complicated for a system with separated electronic components than for a unitized system. Although the provision for physical mobility is recognized as unique to each application and reactor and is therefore beyond the scope of the present applications study, the installation of a scanner with physically separated transmitter and receiver components is generally regarded as impractical unless the installation is done as part of reactor construction.

- The installation of an acoustical device with a separated transmitter and receiver to scan an object between the two presupposes that the location and size of the object in question are known. Such a system, therefore, cannot be considered for missions involving searches for missing pieces or for foreign objects.

Though not entirely excluded from consideration, the scanner with a separated transmitter and receiver is regarded as being useful only when a specific application is foreseen at the time of reactor design and when the system is installed during the construction of the reactor. Since a majority of the individuals interviewed in the course of this applications study were prone to visualize applications in existing facilities, the greater flexibility of the unitized device appears to be an overriding asset. 


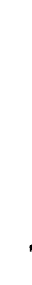

.

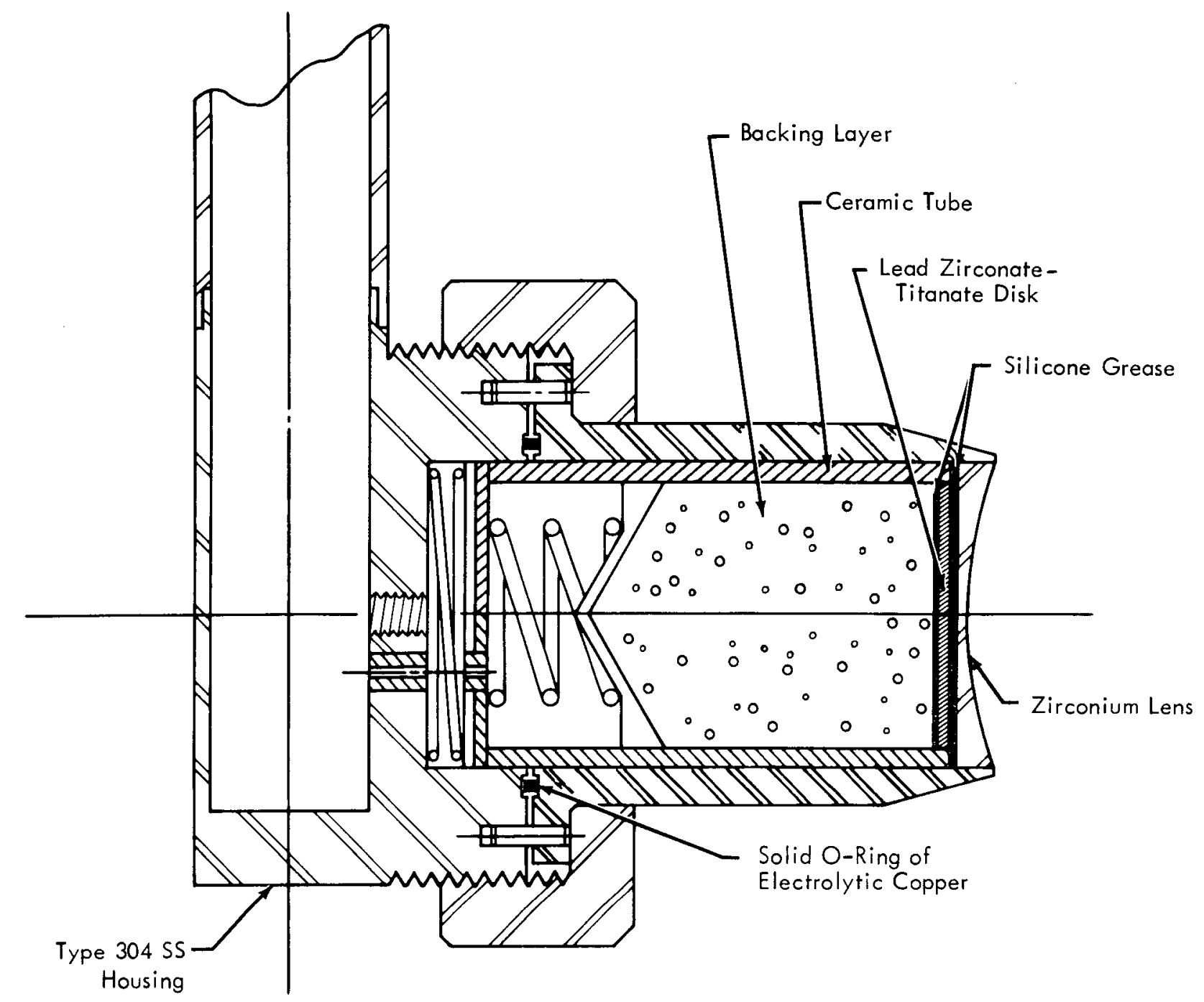

FIG. 1 FOCUSING TRANSDUCER WITH METAL LENS 
For ultrasonic search beams to be useful in sodium, absorption of the ultrasonic energy must be small to allow a significant fraction of the energy to be transmitted over distances large enough for scanning. Measurement of the absorption coefficient was made in a sodium tank facility (Fig. 2) constructed at the APDA Test Site at Trenton, Michigan. In this work, an ultrasonic generator was used to transmit energy through a sodium volume into a receiver. Sodium temperatures ranged up to $600 \mathrm{~F}$. Results, as shown in Fig. 3, indicated that actual absorption of ultrasonic energy in liquid sodium agreed well with theoretically derived values. From the frequency normalized values of Fig. 3, a graph of relative transmitted beam intensity was constructed (Fig. 4). This graph indicates that, for transducer frequencies between 1 and $3 \mathrm{Mc} / \mathrm{sec}$, beams can be transmitted up to 10 feet and more with no significant loss in intensity. At higher frequencies (up to $10 \mathrm{Mc} / \mathrm{sec}$ ), which are used to obtain narrower beams, transmitted intensity will be sufficient up to one foot. In summary, the measured absorptive properties of sodium were found to be quite satisfactory for the use of long-distance search beams.

In developing the unitized transmitter-receiver concept, studies were made from which materials could be selected for the lens, piezoelectric crystal, backing, and construction.

From these studies, an acoustic lens of zirconium metal was chosen to focus the beam. In addition to being essentially inert to high-temperature sodium, zirconium has desirable focusing properties. To focus a beam, a lens must have an index of refraction (ratio of the velocity of sound in the lens to that in sodium) significantly different from unity, and preferably about 1.5 to 2.0 . Zirconium has a satisfactory index of 1.92 in sodium. Further, it has an acoustic impedance (product of velocity and density) very similar to that of sodium, which is required to permit the transfer of energy to the sodium.

Sound velocity in sodium was measured 2 (Fig. 5) and found to be rather low compared to most metals. Therefore, for most metals including zirconium, iron, nickel, stainless steel, and tungsten the interface between sodium and reactor internal parts will constitute a strong source of reflection to the acoustic beam. The echo would be returned to the device and refocused by the lens for reception by the source-detector.

Crystal performance studies 1 confirmed a lead zirconate-titanate ceramic, available commercially as PZT-5, as the most desirable piezoelectric material. Its curie temperature is $690 \mathrm{~F}$, and its overall perform- 


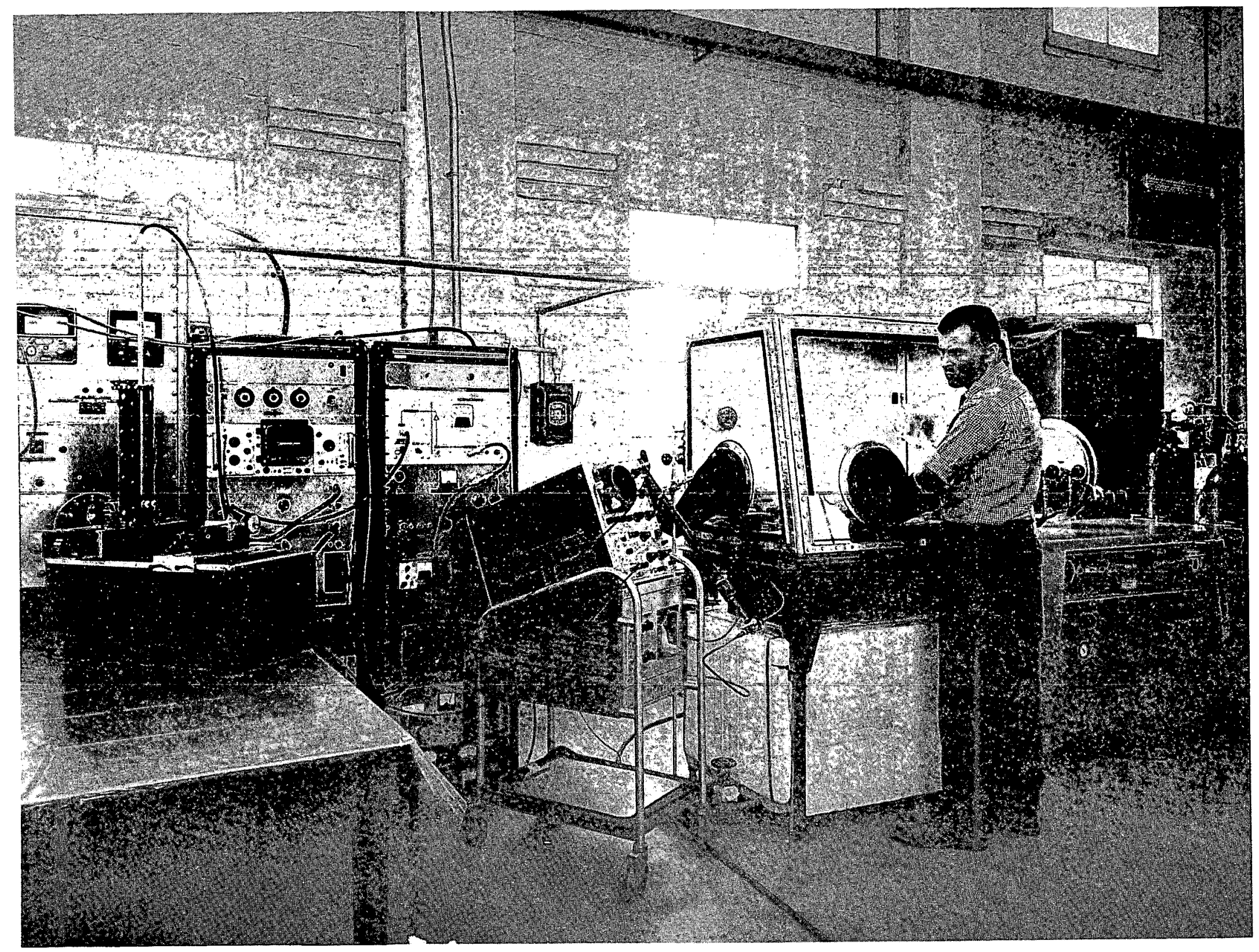

FIG. 2 UNDER-SODIUM ULTRASONIC SCANNING TEST FACILITY 


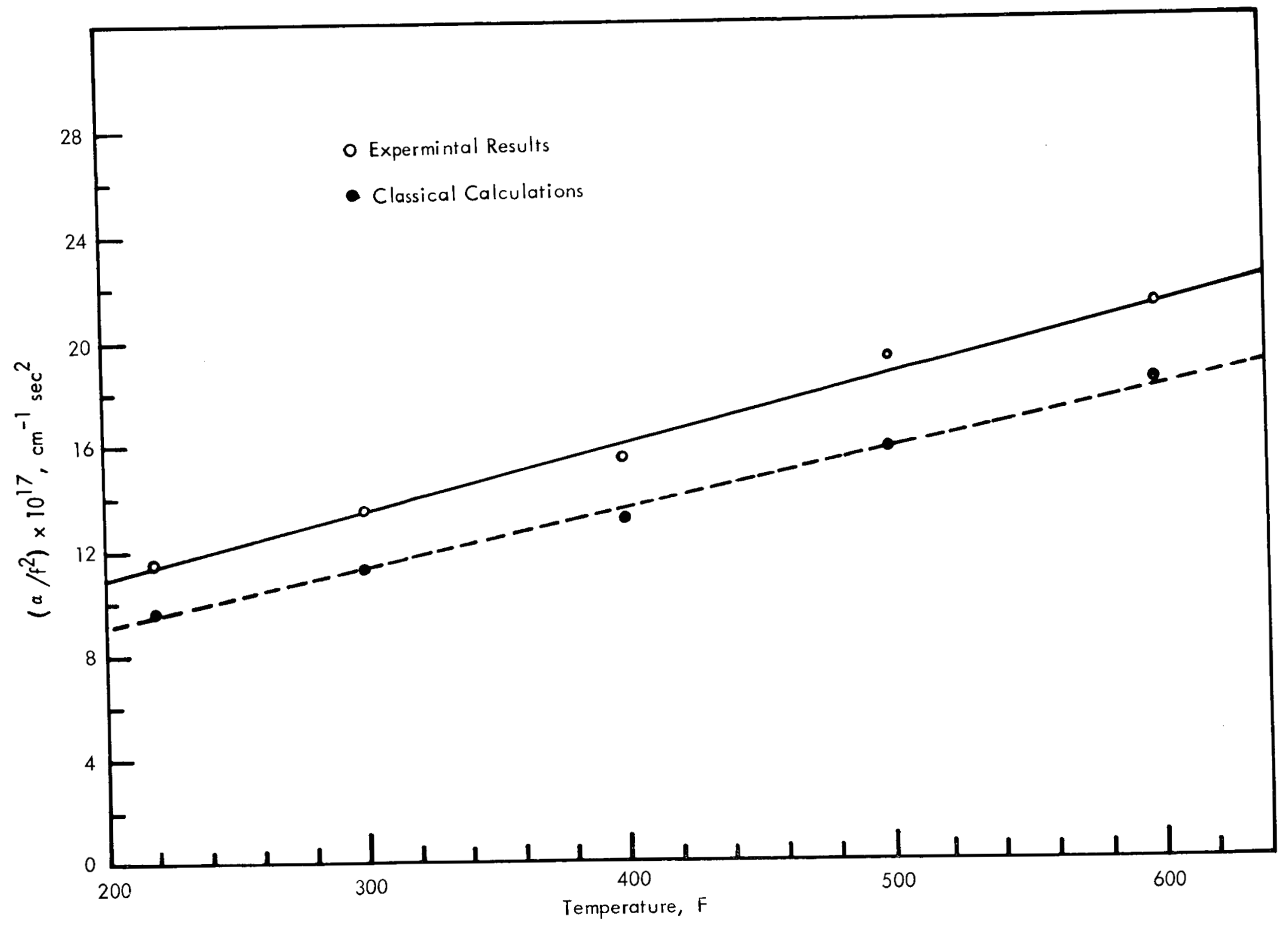

FIG. 3 ULTRASONIC ABSORPTION IN LIQUID SODIUM 


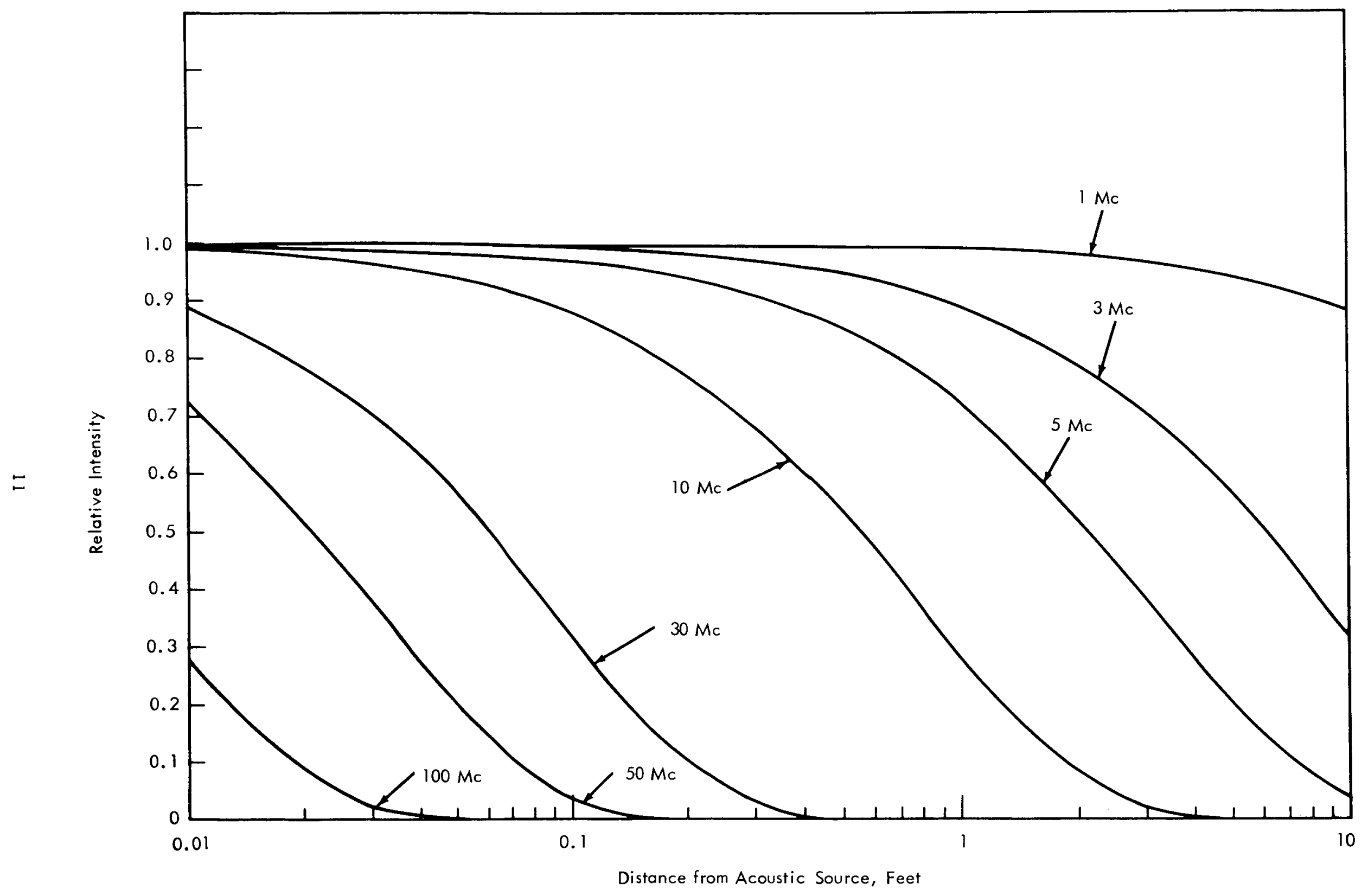

FIG. 4 INTENSITY ATTENUATION IN LIQUID SODIUM 


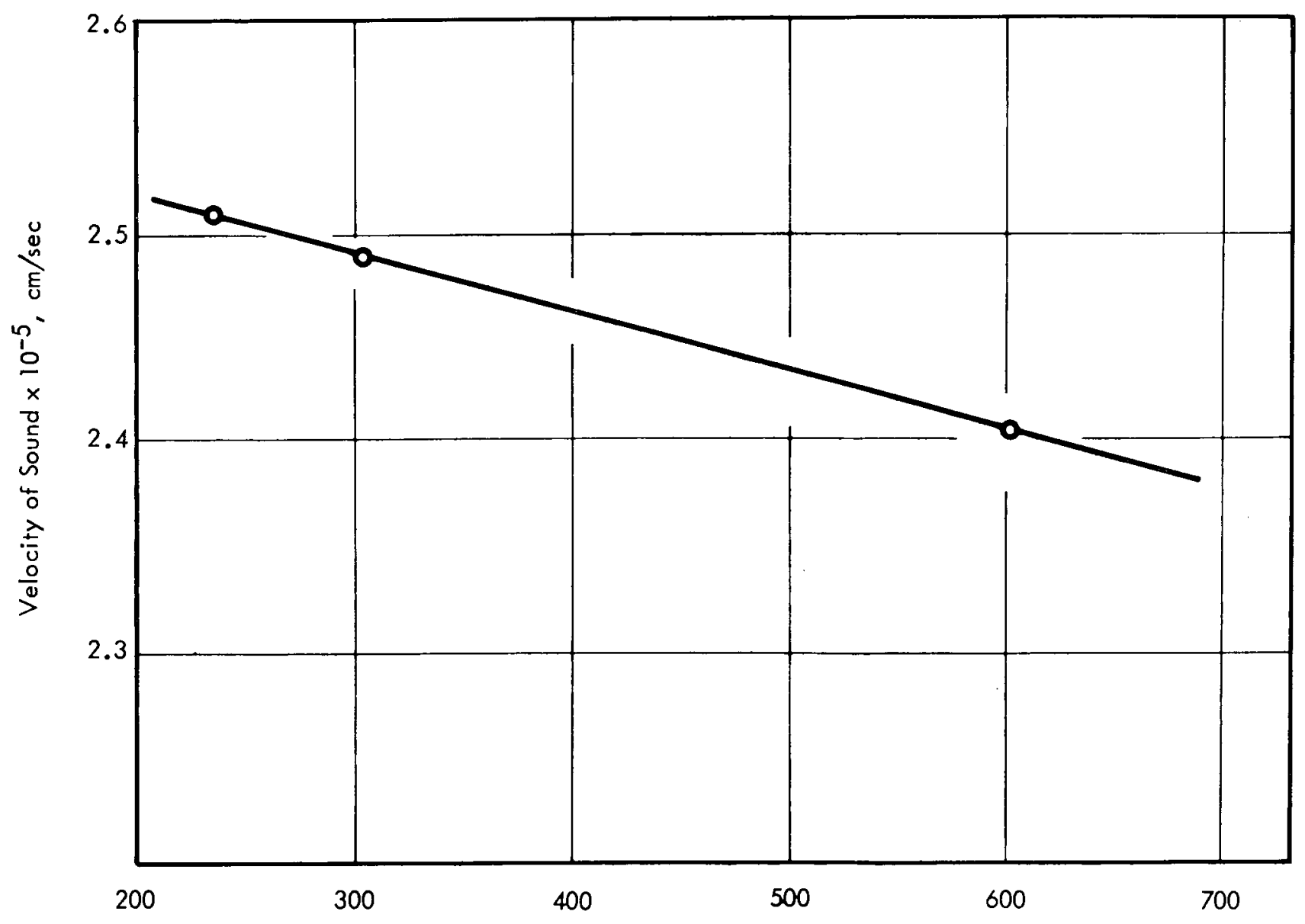

Temperature, $F$

FIG. 5 VELOCITY OF SOUND IN LUUID SODIUM 
ance to that temperature is satisfactory. Studies elsewhere have shown the existence of another material that would operate at temperatures greater than $2000 \mathrm{~F}$.

A backing of zinc was selected because its acoustic impedance matches that of PZT-5. Unwanted sound transmitted through the backface of the piezoelectric crystal is therefore absorbed into the zinc. A typical backing layer is shown in Fig. 6.

Commercial electronic pulse generation and echo reception circuits have been employed. Refined, special purpose systems were developed. 4,5

An appropriate sodium tank was designed and constructed and all parts necessary for demonstrations of the narrow-beam ultrasonic transducer were constructed and assembled, including crystals, lenses, and other parts with a variety of dimensions. Parameters included lens radius of curvature, crystal dimensions, and sonic frequencies. Initial testing began in water with an investigation of the A-scan mode of operation. In this work, an oscilloscope was used to display the electroacoustic signal. Time for the signal to make a round trip to and from a target in the water medium was displayed on the $\mathrm{X}$-axis of the oscilloscope. Results indicated that strong return signals occurred as expected and could be measured to a distance of 20 inches, with the only limitation being the walls of the tank. Beam shapes and parametric variations were studied. 7 For example, effect on beam width of a change in lens radius of curvature is shown in Fig. 7 for a 0.187 -inch-diameter steel rod target.

Studies of the basic device have been conducted in the tank facility up to $600 \mathrm{~F}$. They constitute feasibility demonstrations of the device and the construction technique in high-temperature sodium. The signal from a 2.25Mc PZT-5 crystal with a zirconium lens of 4 -inch radius of curvature is displayed in Figs. 8 and 9. At the maximum temperature the signal is strong, with a high signal-to-noise ratio. In Fig. 9 the target is a 0.187-inch-diameter rod, effectively a line target, 12 inches distant from the device. Difficulties previously experienced from a lack of wetting the lens in sodium were alleviated by an acid-etch cleaning of the lenses. The device performed over a period of 24 hours during which the temperature was raised from 300 to $600 \mathrm{~F}$ and held for 5 hours. When removed at $300 \mathrm{~F}$, the device was still operating and demonstrated a noticable improvement over the initial performance at $300 \mathrm{~F}$. Beam width was measured at $600 \mathrm{~F}$ and was found to be less than $3^{\circ}$ (at the $3 \mathrm{db}$ points). Further investigations will be made at $600 \mathrm{~F}$ to examine detailed characteristics under these conditions. A parametric study will be performed to confirm the finding that, as expected, in-sodium measurements can be predicted in a straight-forward manner from water measurements. 


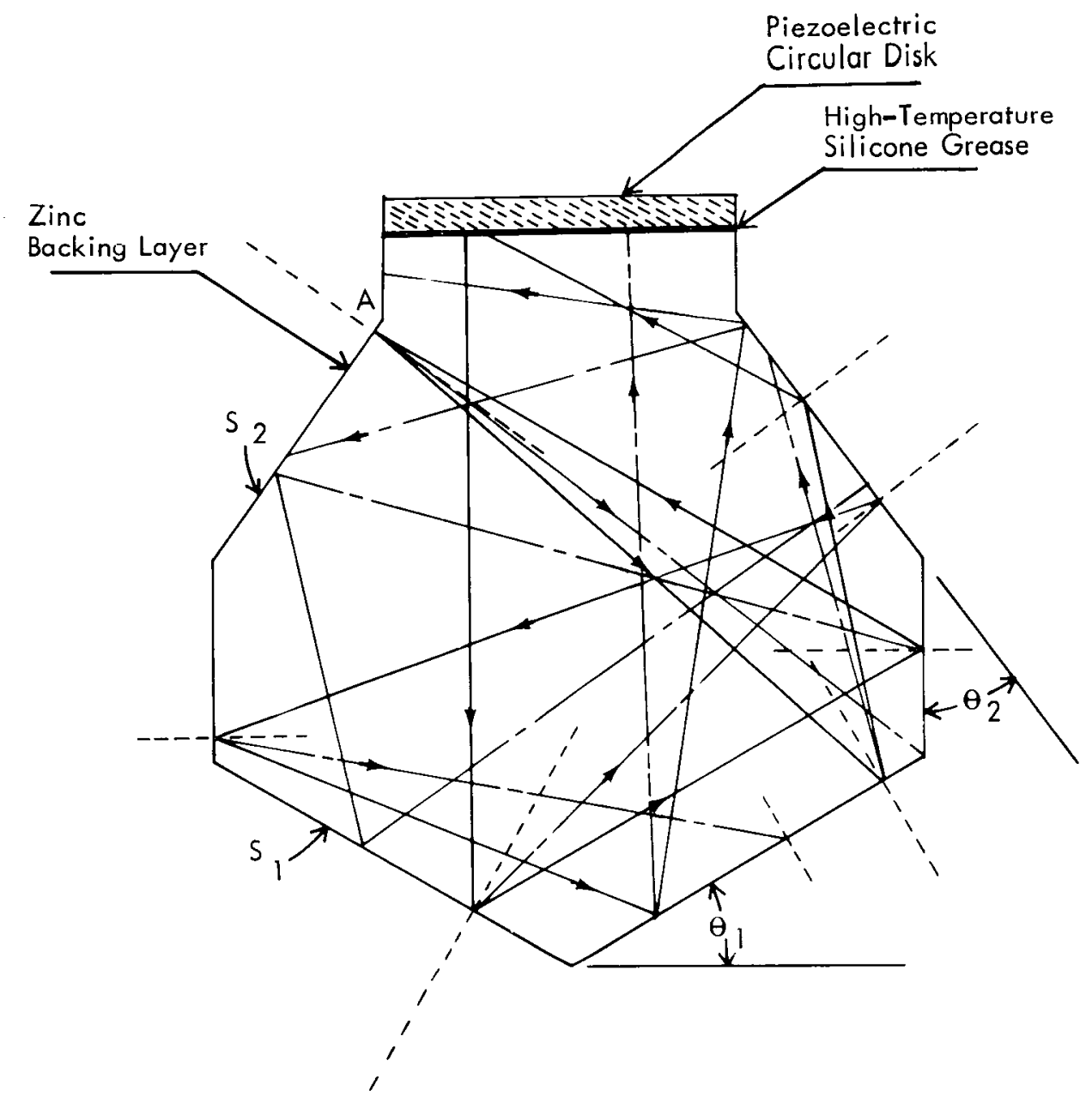

Path of Longitudinal Wave
$\ldots \ldots+$ Path of Transverse Wave
Normal Line of Surface

FIG. 6 A TYPICAL RAY PATH IN BACKING LAYER 


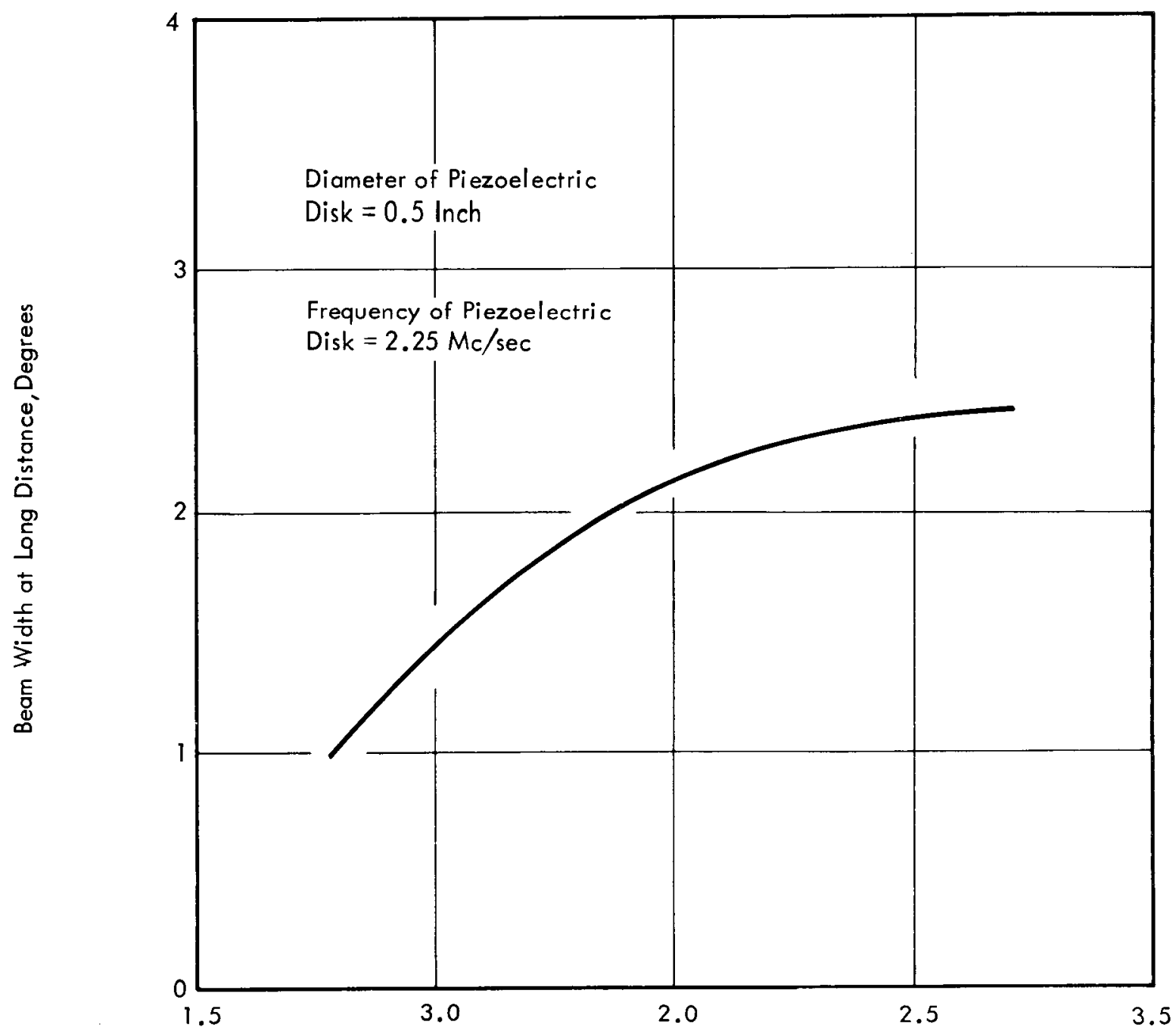

Radius of Curvature, Inches 


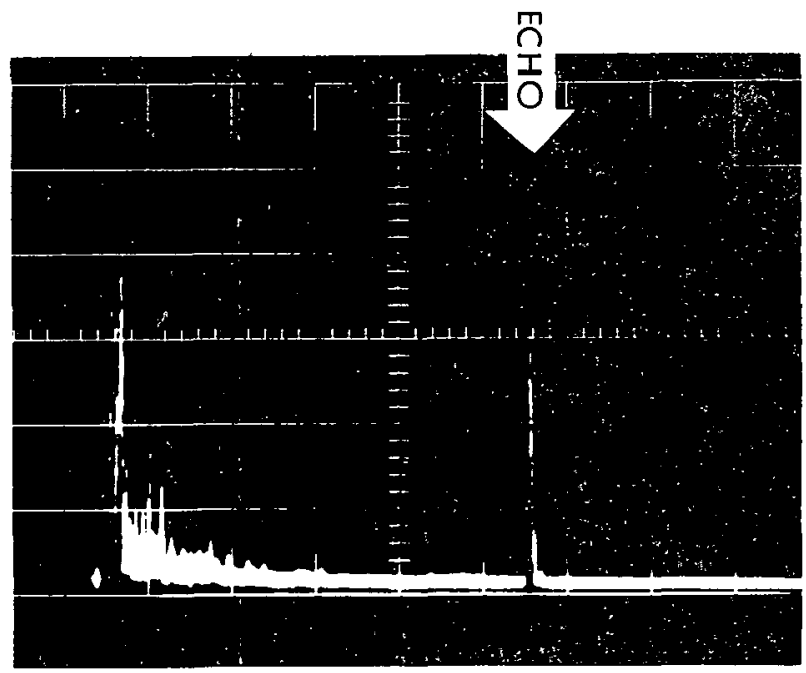

Transducer-to-Wall Distance, 21 Inches;

Oscilloscope Sweep Rate, $100 \mathrm{Mi}$ croseconds per Major Division

FIG. 8 NARROW-BEAM TRANSDUCER RETURN SIGNAL FROM TANK WALL IN SODIUM AT $600 \mathrm{~F}$

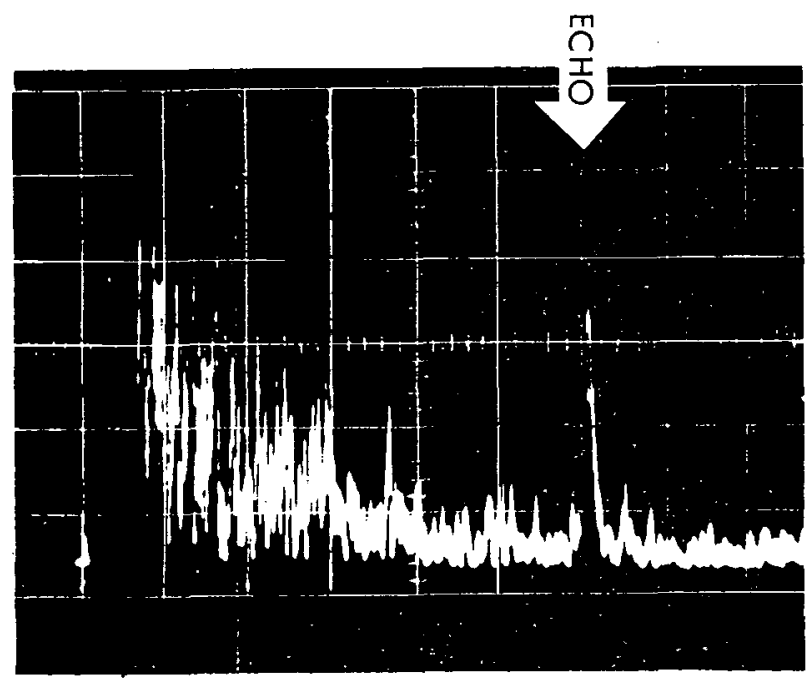

Transducer-to-Target Distance, 12 Inches; Oscilloscope Sweep Rate, 50 Microseconds per Major Division

FIG. 9 NARROW-BEAM TRANSDUCER RETURN SIGNAL FROM TARGET ROD IN SODIUM AT $600 \mathrm{~F}$ 
The $\mathrm{C}$-scan mode of operation adds a geometrical dimension to signal display capabilities. A system was designed and purchased in which a narrow-beam device is mechanically moved across a target and its signal recorded on an X-Y plotter. Results taken in a water environment 7 are shown in Fig. 10. Letters 1/4-inch wide and 1/4-inch deep were milled in an aluminum bar. The scan was performed with a transducer having a 4.5-inch focal length and with a 5-Mc crystal. In-sodium scanning experiments are currently underway.

Recently, work has been performed on the signal quality of the device. While the signal has been demonstrated to be quite adequate for all of the investigations discussed here, it is nevertheless capable of improvement. Signal-to-noise ratio and beam time duration (hence, distance resolution capability) can be improved. Earlier results showed significant reduction in signal width. Conclusions of the study were that a reduced density material will make a better backer-absorber. A proposed construction method for a backing of continuously varying density manufactured from a powdered ceramic of varying powder size has been generated and a potential fabricator located. Such a material should result in a significant improvement in the acoustic response.

The only known limitation in the operating time of the device results from use of the high-temperature grease used for acoustic boriding. A study to investigate a replacement bond has been completed. A brazing technique using indium metal to bond the crystal surface (which is silver-coated) to the acoustic lens is recommended. The metal layer will be electrochemically deposited to a thickness of about $10^{-4}$ inch. 


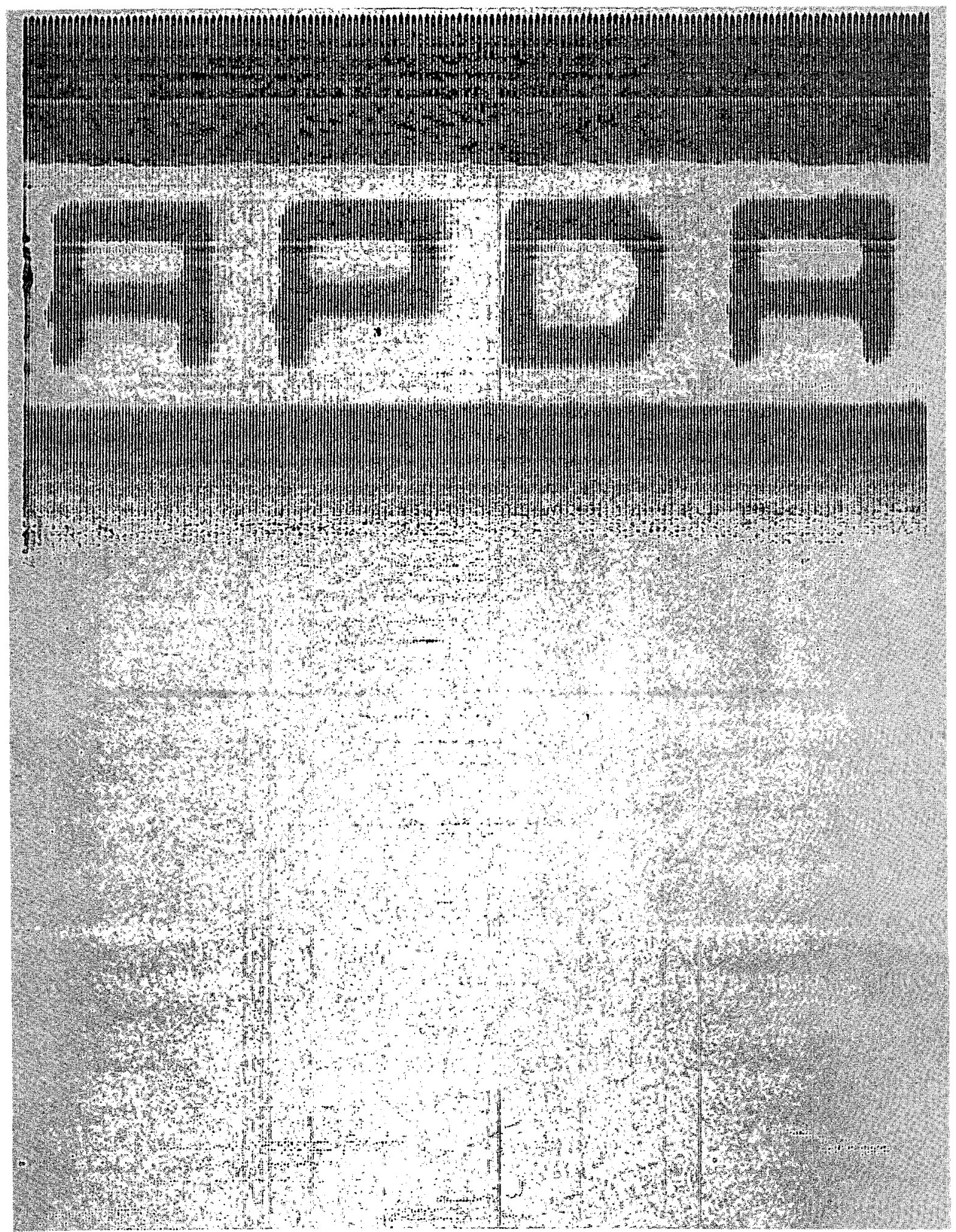

FIG. 10 ULTRASONIC C-SCAN IN WATER 
IV. CAPABILITIES AND LIMITATIONS OF THE DEVICE

In the course of the development work conducted at APDA to date, 12 focusing transducers in a variety of sizes have been built and tested. On the basis of this experience, the minimum size of a workable transducer for use as a general purpose under-sodium ultrasonic scanning device is about 2 inches long and $1-1 / 2$ inches in diameter. This size, therefore, represents the first limitation: namely, the minimum size of the plug penetration needed to insert the device into a reactor which, it is assumed, was built without this specific device in mind. If this size is prohibitive, the head diameter could be reduced to approximately $3 / 4$ inch with a minimum of redesign effort. Commercial transducers as small as 0.030 inch have been built.

The range of the device, i.e., the maximum practical distance between the transmitter-receiver and the object being scanned, is limited by the absorption of the transmitted and reflected signal by the sodium through which it travels. As indicated by the sodium attenuation studies mentioned in Section III, the range of the scanning device is, in general, inversely proportional to the square of the frequency, and when the round trip distance is less than 10 feet, the problem of attenuation can be ignored at frequencies less than $1 \mathrm{Mc} / \mathrm{sec}$.

From the standpoint of resolution, it would be desirable to operate at high frequencies. For example, the wavelength of a $2 \mathrm{Mc} / \mathrm{sec}$ ultrasonic field in liquid sodium at $600 \mathrm{~F}$ is about $0.121 \mathrm{~cm}$, while at $20 \mathrm{Mc} / \mathrm{sec}$, it is one-tenth that value (the resolution is 10 times as good). In search of a compromise between range and resolution for this general purpose scanner, a frequency of $2 \mathrm{Mc} / \mathrm{sec}$ was adopted as the reference value. As shown in Fig. 11, the round trip distance at which the transmitted beam has been attenuated to half its original intensity is more than 100 inches (actually about 150 inches) for the $2 \mathrm{Mc} / \mathrm{sec}$ frequency. Therefore, the maximum range of the device, stated as the maximum practical distance from the transducer to the object being scanned, is about 6 feet. For specific applications, resolution can be improved at the expense of range by selecting a higher ultrasonic frequency or vice versa with a lower frequency.

Depending on the radius of curvature of the lens, the device also has a minimum working distance corresponding to the focal length of the lens. Again this becomes a design option but experience suggests that approximately 4 inches is a good focal length to use in a general purpose scanner. At lesser focal lengths, the sharpness of the focus is not well defined. 


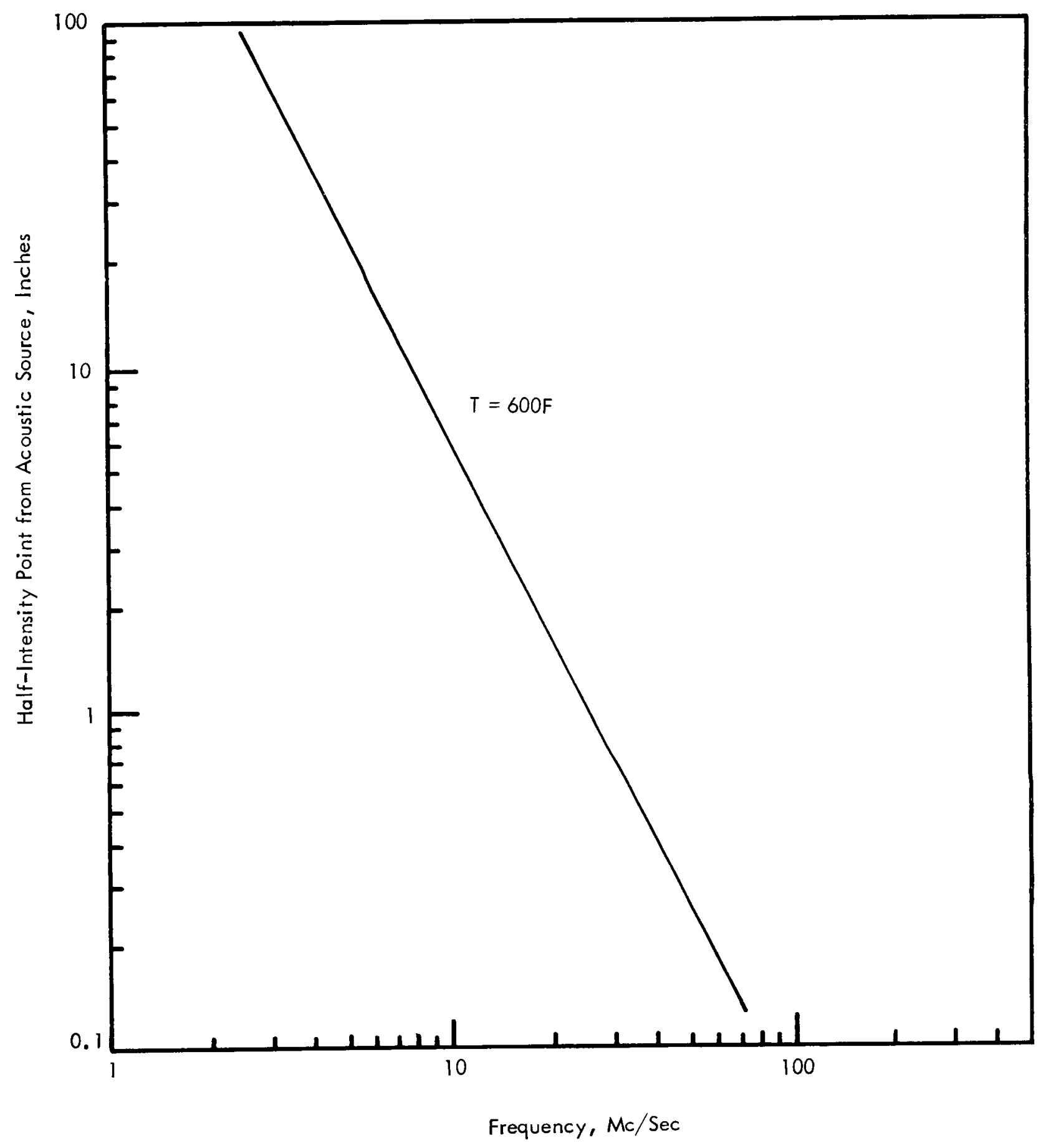

FIG. 11 HALF-INTENSITY POINT FROM ACOUSTIC SOURCE IN LIQUID SODIUM 
As previously metioned, PZT-5 was found to have more suitable properties for a piezoelectric crystal in the device than several other ceramics studied. Quartz was found to have both a higher tensile strength and curie point than PZT-5, but it has two serious limitations: the material displays a decreasing piezoelectric activity above $500 \mathrm{~F}$, and it has low piezoelectric coupling that severely impedes bandwidth. The curie point, i.e., the limiting temperature piezoelectric effect, is $690 \mathrm{~F}$ for $\mathrm{PZT}-5$, which represents an absolute temperature limitation on the device. Nominally, however, the temperature limit is quoted to be $600 \mathrm{~F}$ which should be adequate for service in nonoperating sodium-cooled reactors. For applications requiring service at higher temperatures, an alternate piezoelectric material must be selected with some attendant sacrifice in other properties.

In the A-scan mode, the location of an object, i.e., its distance from the device, is obtained from the time separation between the transmitted pulse and the echo on the sweep of an oscilloscope. Figure 12 shows a typical display of the two pulses. The translation of the echo time lag into distance requires knowledge of the velocity of sound in liquid sodium and the accuracy of the method is no better than the knowledge of this property. Though this property is known (Figure 5), the element of uncertainty in sonic velocity owing, for example, to an uncertainty of the temperature of the medium, may be large relative to the accuracy desired. In such cases, an in situ calibration can be made by beaming the signal at an object of known location, i. e., the vessel wall. (It is always assumed that the exact location of the device will be known.) By thus eliminating any uncertainty that may exist in the velocity of sound, the distance from the device to the object can be resolved to within a few mils at a nominal distance of 1 foot.

Because of the acoustic impedence mismatching at both surfaces of a metal plate in liquid media, two reflections, one from each surface, appear on the oscilloscope screen in the A-scan display. The thickness of a metal plate can therefore be determined by the time separation of the two reflected pulses on the oscilloscope screen and the knowledge of the velocity of sound in the metal plate. The estimated minimum thickness that can be accurately read is 0.030 inch for steel. By the same principle, the distance between two objects located a'long the same ultrasonic beam can be deduced from the oscilloscope display.

A general search for missing or foreign objects would be conducted in the A-scan mode. The key to success lies in the interpretation of the display of reflected pulses. To locate an object in an area with a complicated background -- for example, a subassembly that has been inadvertantly dropped to the bottom of a reactor vessel - - drawings of the structure must be available and carefully studied so that sources of extraneous reflections can be identified. 


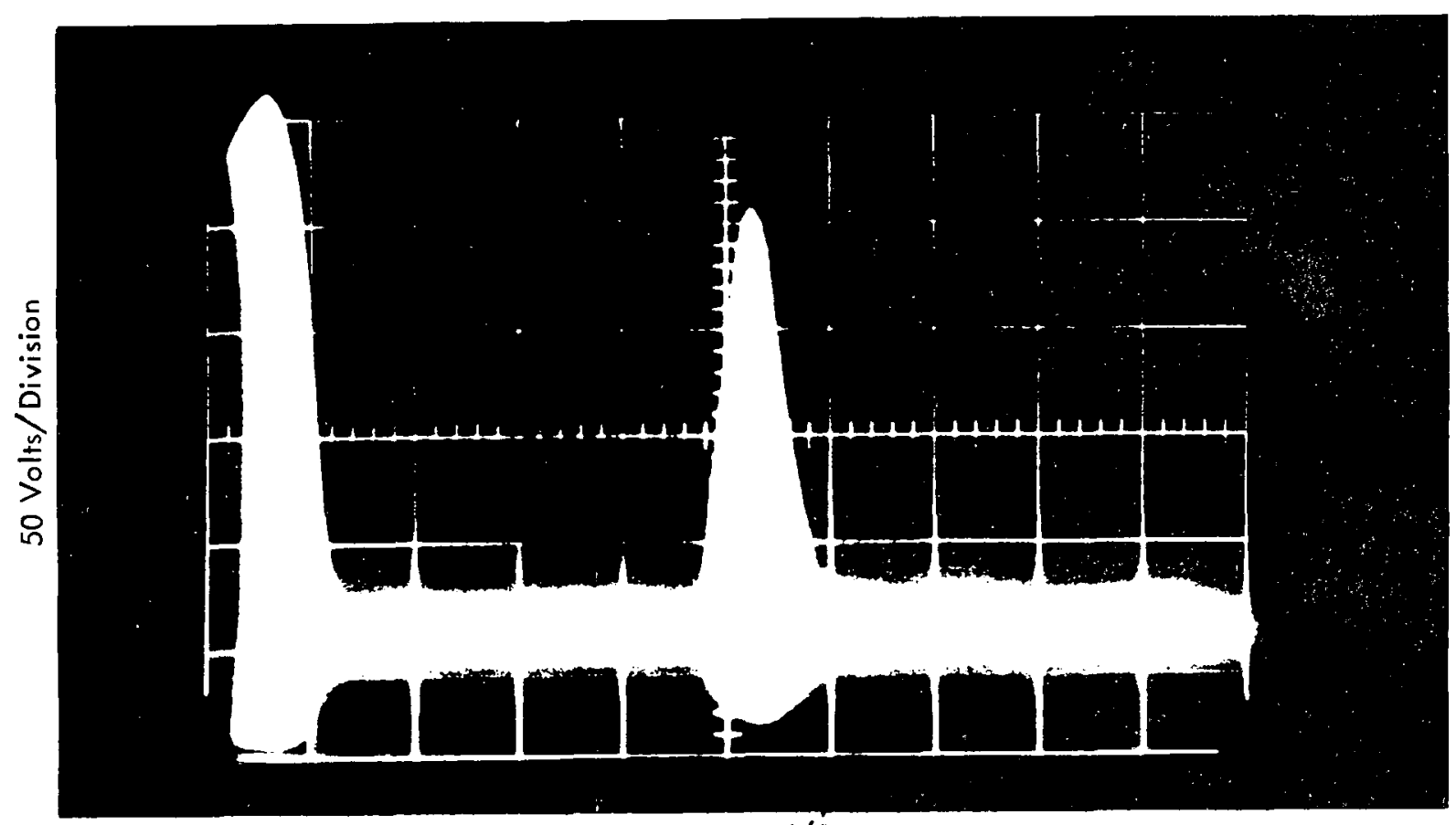

$20 \mathrm{Microsecond/Division}$

FIG. 12 TYPICAL SIGNAL OBTAINED FROM TRANSDUCERS OPERATING IN LIQUID SODIUM 
In the $\mathrm{C}-\mathrm{scan}$ mode, the transducer emits pulses of ultrasonic energy as it traverses a plane opposite the object being scanned. By utilizing the reflected energy from an incident beam striking an object, i.e., normal reflections from the object, the image of the object can be produced on the $\mathrm{C}$-scan recorder. In the more general application, where the surface of the scanned object is curved or otherwise not normal to the incident beam, the energy reflected will not return to the transducer. Instead it will form the acoustic shadow characteristics of the frontal projection of the object against a background reflector which is essentially parallel to the travel plane of the scanner. Some objects will create both effects when fully scanned. Portions of the surface that are either normal or very close to normal to the incident beam will reflect directly to the transducer and other portions of the surface will create a shadow against the constant background reflection.

The criteria for successful C-scan operation, therefore, is that eithe $x$ the object being scanned or the background must be normal to the travel plane of the transducer. By orienting the transducer so that it beams essentially along a radius of the reactor vessel, i.e., the vessel wall, a background reflector can be effected, provided the wall is smooth and unperturbed in the area in question. Assuming the object being scanned is very small relative to the vessel, the device can track in an X-Y plane and the vessel wall directly behind the object will be sufficiently perpendicular to the beam to provide a good reflection. Even when scanning objects with complex surfaces that are partly normal to the beam and partly not normal, the interpretation of the C-scan display should not be prohititively difficult.

An important detail likely to cause further limitations in using the device is the auxiliary mechanical system needed to implement each specific application. In A-scan applications, the device must be positioned in and generally moved with $X, Y$, and $Z$ freedom in the region of the reactor that contains the object to be scanned. Also, for many applications, the device should be gimballed so that it may search, as an eye is capable of searching from a fixed head, for surfaces that are normal to its emitted beam. For meaningful results, the absolute location of the device and the direction of its emitted beam must not only be controllable but accurately known.

For the C-scan mode of operation, the operator must have, in addition to the above movements for initial positioning, the ability to program the travel of the device so that it traverses and beams out from a two-dimensional route that can take the form of a rectangle, a curved portion of a cylinder, or a portion of a sphere. The consideration of the means of providing this necessary supporting system is beyond the scope of this applications study, but the authors are aware that such problems are formidable and may curtail applications that are otherwise feasible. 
In the previous paragraphs, generalizations concerning the capabilities and limitations of the general purpose under-sodium ultrasonic device developed at APDA have been presented. In the following sections, the device is considered for specific applications in sodium-cooled reactors. 


\section{SURVEY OF POTENTIAL APPLICATIONS FOR THE DEVICE}

To compile, with the greatest possible thoroughness, a list of potential applications for the under-sodium ultrasonic scanning device, the authors conferred with over 30 specialists in sodium-cooled reactor design, maintenance, instrumentation, and control. These individuals, whose collective assistance proved invaluable in this task, represented in approximately equal numbers Argonne National Laboratory, Atomics International, Battelle Northwest Laboratories, and Atomic Power Development Associates. In general, all contributors were intimately familiar with one or more of the following reactors: Fermi, EBR-II, FFTF, SRE, and Hallam.

The proposed applications in the following list were screened by the authors. Those applications found to be clearly beyond the present level of technological development of the device were deleted. With the applications presented, parenthetical explanations are included where required. The applications are listed in no particular order and evaluation is deferred to Section VI.

1. In-core identification of subassemblies. (Read identification numbers using $\mathrm{C}$-scan mode.)

2. In-core determination of orientation of subassemblies or other remotely handled components. (Monitor direction of arrowhead or orientation of identification number using $\mathrm{C}$-scan.)

3. Employ scanner as a substitute for a mechanical sweep to obtain periodic assurance that subassembly heads are not projecting above their normal elevations. (Sweep $360^{\circ}$ along radii of reactor vessel using A-scan mode.)

4. Primary signal for auto-control of a mechanical device such as the subassembly handling mechanism. (A voltage proportional to the distance between the transducer and the subassembly can be used to operate the handling mechanism. The transducer, operated in the A-scan mode, can be programmed to move along the desired path for the subassembly. As the transducer moves in a direction that causes a reduction of signal because of reduced sound reflections from the subassembly, the handling mechanism can be made to follow the transducer orientation. The device can also provide positive indication of gripping and release of subassemblies.)

5. Calibration of mechanical means of mechanism control. (If, instead of using the device for auto-control of mechanisms as explained in application No. 4, the designer prefers to retain con- 
ventional methods of positioning handling mechanisms, the ultrasonic scanner can still be used for initial and, if necessary, subsequent calibration of drive controls.)

6. Search for missing objects and retrieval guidance. (When an object is known to be missing from its normal position $X$ and believed to have been displaced by pump action, gravity, or other force to region $Y$, use $A-s c a n$ mode to search region $Y$. )

7. Search for deleterious foreign objects. (Example: Perform periodic A-scan sweep of coolant feed plenum to monitor for possible sources of flow-blockage. If such an object is located, perform C-scan determination of its size and shape to analyze possible danger of its presence.)

8. Periodic inspection of support plates. (With A-scan distance determination from a fixed plane, support plate warpage can be measured. With C-scan image display, the condition of support plate holes can be periodically monitored for evidence of cavitation damage, etc.)

9. Inspection of reactor vessel welds. (During reactor construction provisions can be made for a transducer and a mechanical track adjacent to one or more critical vessel welds. The weld seam can then be monitored for cracks with A-scan measurement of effective thickness of vessel wall.)

10. Use ultrasonic device as an in-line impurity meter. (Attenuation of signal, and therefore strength of echo from a constant reflector, is sensitive to sodium purity. A device could thus be installed in a fixed position at pump discharge for a continuous impurity monitoring role. The feasibility of this application has been qualitatively confirmed but additional empirical work would be required to determine the sensitivity of sound attenuation to concentration of various contaminants.)

11. Level device in various sodium-filled tanks and vessels. (By installing the transducer in a fixed position below the lowest expected sodium level and directing the energy pulse to strike the free surface at right angles, the A-scan distance determination can provide an accurate measurement of the quantity of sodium in the tank. By doing this in all tanks, a nearly continuous material balance on primary coolant can be made. Under some conditions, this material balance would provide the earliest indication of a primary system leak.) 
12. Use two complementary transducers as a sodium flowmeter. (Sonic flowmeters are already available that operate on the principle of comparing the velocity of sound with and against the direction of fluid flow. The difference can be related to the fluid velocity.)

13. Monitor dimensional changes of objects. (Example: Bulging of Hallam moderator cans could be detected by A-scan of a top surface.)

14. Rapid scram signal for subas sembly disengagement accidents. (If a subassembly is ejected from its normal seat position due to failure of a hydraulic or bottom mechanical holddown feature, it could be made to interrupt a standing wave pattern sent out by a nonfocusing transducer and thereby initiate a scram signal.)

15. Monitor potential gas entrapment zones of various primary system components. (Some sodium-cooled reactors have had gasrelease spurts after buildup of gas in stagnant regions of the primary system. An ultrasonic device, either inside or outside the wall of the component vessel in question, is a possible tool with which to monitor the development of a potentially dangerous gas bubble.)

16. General purpose damage assessment. (After an operating incident in a sodium-cooled power or test reactor, there are numerous potential applications for the ultrasonic scanning device when the circumstances are such that the sodium level cannot be lowered for direct viewing. In the FFTF, for example, the problem likely to produce the longest unscheduled outage is the inability to extract a test subassembly from its process tube. It may be possible to determine the magnitude of the problem by lowering a scanning device into adjacent tubes. The subassembly pairing that occurred in the Fermi incident of October 5, 1966, could be similarly viewed.)

17. Inspection of subassemblies prior to steam cleaning. (To avoid a violent exothermic reaction when steam or water is directed into a subassembly which, due to oxide plugging or similar reason, failed to drain, an unfocused ultrasonic beam can be directed at one side of the subassembly near its lower end and received at the opposite side. The medium between transducers, whether gas, sodium oxide, or sodium, can be determined from the strength of the received signal.) 
18. Resolve uncertainties of exact location of certain reactor components. (Example: In the Fermi reactor, there is some uncertainty in the axial location of the ends of core outlet thermocouples in their respective holddown fingers, resulting in an uncertainty of interpretation of the temperature readings. With the A-scan mode, these locations could be positively fixed.)

In the following applications, the ultrasonic scanning device could be used as a research tool in sodium-cooled reactor research and development support programs:

19. Measure tube wastage rates in sodium-water reaction tests on steam generator mock-ups. (Mount ultrasonic device on one side of the target plate and direct a water jet at the opposite surface. With continuous A-scan operation during the dynamic test, measure the target plate wastage rate by monitoring change of thickness.)

20. Out-of-pile fuel-meltdown studies in sodium. (The test section of a sodium loop in which simulated fuel is to be melted by resistance or induction heating can be liberally instrumented with ultrasonic transducers to collectively produce the pattern of fuel movement.)

21. Use ultrasonic transducer as a boiling detector. (In many basic liquid metal heat transfer research studies, it is desirable to know the exact time of initiation of nucleate boiling. Though this is an application that requires special cooling or the development of a high-temperature piezoelectric material, the ultrasonic scanner could, in principle, provide this detection by using the sharp change of acoustic properties of liquid metal as boiling begins.)

22. Use ultrasonic transducer as a cavitation detector. (The principle of detection is the same as with the boiling phenomenon without the associated problem of high-temperature operation.) 


\section{EVALUATION OF POTENTIAL APPLICATIONS AND RECOMMENDATIONS FOR FUTURE WORK}

Referring to the list of applications in Section $V$, numbers 1 and 2 are fairly important, especially in EBR-II and Fermi which are, or will be, used for fast reactor fuel testing. The same need can be anticipated for FFTF, although in the present stage of design it is not possible to determine whether this need can be met with an alternate (visual or mechanical) approach. In the Fermi reactor, for example, it has been deemed necessary to deliberately overcool a fuel test subassembly slated for irradiation beyond the twothirds radius of the core to preclude sodium overheating and possible boiling should it be mismanaged and loaded at the core centerline. An in-core confirmation of subassembly identity prior to startup would remove this necessity and thereby increase the value of peripheral lattice positions. Also in Fermi, the inability to determine the directional orientation of a fuel test subassembly results in an uncertainty of test-channel power (therefore, sodium $\Delta t$ ) of +18 percent at core edge and progressively lesser amounts closed to the core centerline. With an in-core device to determine the orientation of the subassembly and thereby determine the precise position of each fuel-test channel (thimble), this uncertainty can be eliminated. In the EBRII, there is a potential $180^{\circ}$ orientation uncertainty; all other angular positions are mechanically precluded. While this $180^{\circ}$ uncertainty can be eliminated by careful examination of the plug's and gripper's rotational directions and sequences, the protection is not absolute, and for future operation involving fuel test reinsertions, the possibility of orientation error will be greater than it is now.

The ability to read identification numbers, etc., in the C-scan mode has been demonstrated in the earlier development work. Either rectangular or triangular grooves can be cut in a surface normal to the incident beam as shown in Fig. 13. If it is a triangular groove, the transducer will receive reflections from the smooth surface while the beam striking the sides of the groove will be reflected away from the transducer. If the rectangular groove is employed, reflections will be received by the transducer from both the smooth surface and the root of the groove. By using a gating circuit to discriminate the time delay for reflections received from the more distant groove root, the $\mathrm{C}$-scan display can be made to show the engraved message.

Fermi experience has indicated that either a mechanical sweep arm or an ultrasonic scanner (application No. 3) is needed to guard against the possibility of subassemblies clinging to holddown fingers when the holddown mechanism is raised, for this causes damage when the plug is subsequently rotated. This need was filled in Fermi by the sweep arm, but in future reactors the scanning device may be preferred, especially if the device can be given sufficient mobility to meet some of the other applications. 


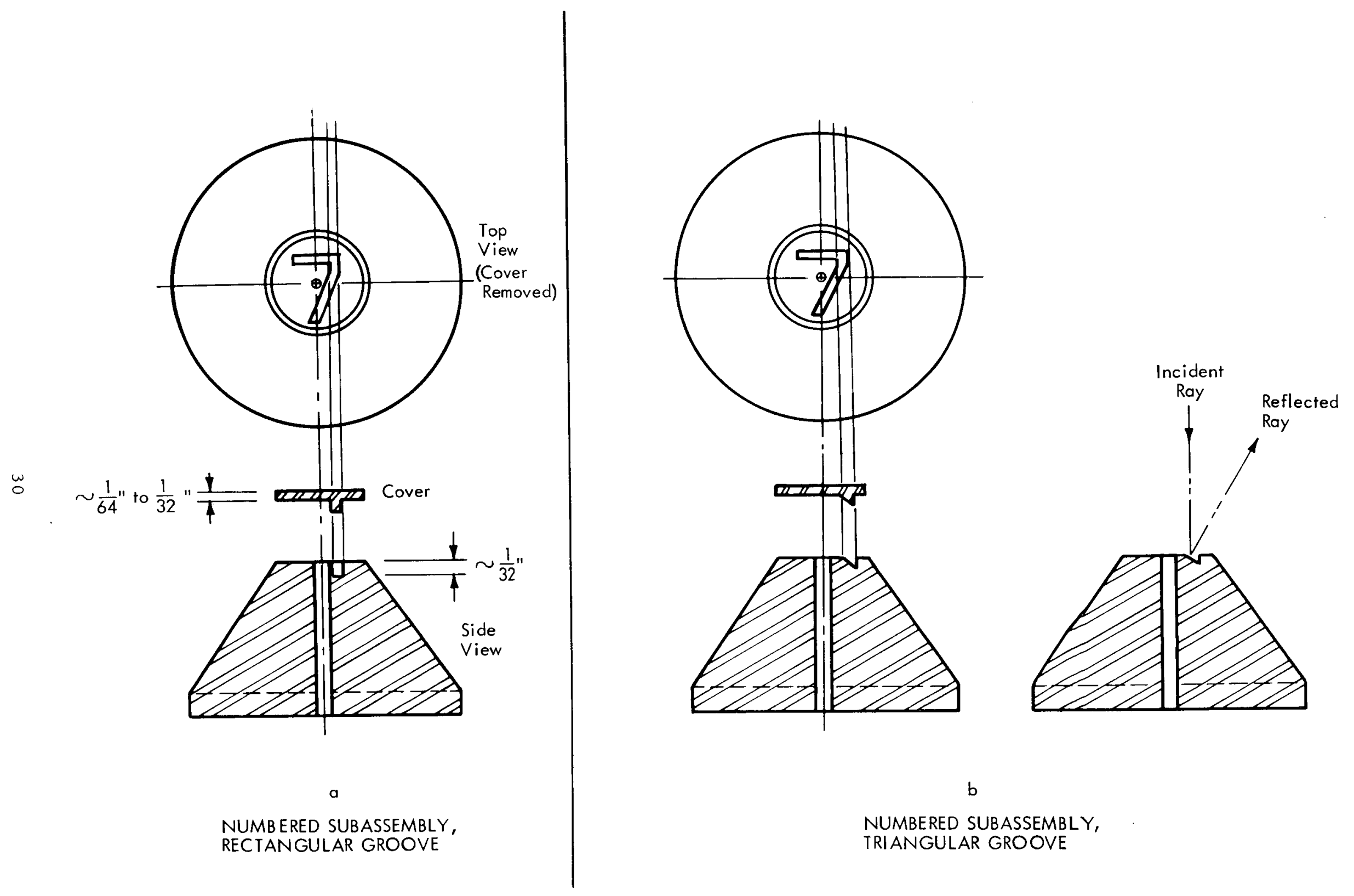

FIG. 13 IDENTIFICATION MARKS ON SUBASSEMBLIES 
Applications 4 and 5 are very possible in future reactors and they could probably be performed with the same device usen in applications 1 and 2 .

Applications 6, 7, 13, 16, and 18 could be met, as far as the upper reactor vessel region is concerned, with a device built into the fuel handling mechanism. The search for missing or foreign objects in the lower plenum region, however, would be a difficult assignment for which to prearrange and even more difficult to add after construction and operation.

Application 8 is fairly important and could be performed after the removal of the subassembly from the specific region of the support plate to be inspected with a device built into the fuel handling mechanism. Except in short cores, it would require a transducer of greater range than any of the other applications in this list.

Application 9 is becoming more important as the AEC regulatory groups turn increasing attention to reactor vessel integrity. With the necessity to provide a scanning device and track for the scanner along each critical weld seam, however, this would be an expensive application to pursue and one that is totally impractical for existing reactors.

Applications 10, 11, 12, 14, and 15 are potentially interesting ways of utilizing ultrasonics for special purpose instrumentation. All are qualitatively feasible, although some would require further development to achieve the desired level of quantitativeness. None, however, satisfy the current objective of identifying an application worthy of follow-on development for a proof-of-principle demonstration of the general purpose usefulness of the ultrasonic scanner.

Application No. 17, though an out-of-pile utilization of the ultrasonic principle, is important and should be satisfied, if not by ultrasonics then by other means such as a sufficiently sensitive load cell. The addition of steam or water to dead-ended sodium pools, such as a subassembly whose nozzle is plugged by oxide contamination, is a highly dangerous activity, and during the brief history of sodium-cooled reactors a few accidents traceable to this cause have already occurred.

Applications 19 through 22 are only examples of ways in which ultrasonic detectors can be used in research and development supporting roles. There are undoubtedly many more promising applications in this category.

In regard to the question of which application or group of applications should be pursued as the near-term demonstration objective for the device, it is recommended, as an initial ground rule, that the application(s) be selected from the in-reactor viewing applications rather than from out-of-pile usages or usages involving ultrasonics in special purpose instrumentation. 
The reason for this recommendation is that once the feasibility of in-reactor ultrasonic viewing is demonstrated, even for a simplified application, a much greater vista of future applications will be appreciated than would otherwise be the case.

The first thing that becomes obvious from the selection of an inreactor application is that more data are needed on the radiation behavior of PZT -5 and other potential piezoelectric materials. A transducer located in a pool (2-foot-diameter sphere or larger) of primary sodium of an operating fast reactor will experience a field of $1 \times 10^{4}$ to $5 \times 10^{4} \mathrm{r} / \mathrm{hr}$ of $2 \mathrm{Mev}$ gammas from $\mathrm{Na}-24$. (Unless the transducer is very close to the core, the Na-24 gammas will constitute the majority of the radiation field strength.) There is no known ratiation data on PZT-5 with which to estimate the useful life of an ultrasonic transducer in such an environment. Irradiation tests, therefore, should be initiated as Phase I of a follow-on development program.

From the preceding evaluation of the applications presented in Section $V$, it can be noticed that the positioning and requisite mobility of the device can be acquired for many of the applications by incorporating the device into the fuel handling mechanism, particularly for reactors with the open upper plenum characteristic of EBR-II and Fermi. It is recommended that the near-term goal for future development focus on the eventual mounting of an ultrasonic transducer in the "palm" of the fuel handling gripper. Preferably, this installation should be made in an existing reactor facility (e.g., Fermi or EBR-II) with a slightly modified gripper. If a reactor is not available, the installation and demonstration will have to be limited to a sodiumfilled reactor mock-up facility.

With only $\mathrm{X}-\mathrm{Y}$ mobility of the transducer (i.e., the transducer always directed vertically downward but capable of traversing the horizontal plane in the upper plenum region) the device could perform applications $1,2,4,5,8$, and to a limited extent, applications $6,7,13,16$, and 18. If the transducer could be given $90^{\circ}$ wrist action so that it can be oriented remotely to beam in the horizontal plane, its usefulness can be expanded to include application 3 and a more thorough coverage of applications $6,7,13,16$, and 18 .

In summary, APDA recommends a two-phase program for the design and demonstration of the A-scan and C-scan modes of scanning. Phase I would include a mock-up facility for the initial design and demonstration program. It is anticipated that applications $1,2,3,6,7,8,13,4$, and 5 , identified in Section V, could be satisfactorily demonstrated in a mock-up facility in the approximate order listed. Parallel with the design and demonstration program, irradiation tests on piezoelectric materials would be conducted in EBR-II or Fermi.

Phase II would cover the design and demonstration of a system in a reactor facility to be selected at some later date. The applications listed for demonstration in Phase I could be repeated. 


\section{REFERENCES}

1. Ying, S. P., and Scott, C. C., "Concepts for General Purpose Under Sodium Scanning Systems," APDA-179, November 8, 1965.

2. Ying, S. P., and Scott, C. C., "Attenuation Measurements of Sound and Performance of Ultrasonic Transducers in $600 \mathrm{~F}$ Liquid Sodium, "APDA180, December 15, 1965.

3. "Quarterly Technical Progress Report on AEC-Sponsored Activities," APDA-182, October-December, 1965.

4. "Quarterly Technical Progress Report on AEC-Sponsored Activities," APDA-185, January-March 15, 1966.

5. "Quarterly Technical Progress Report on AEC-Sponsored Activities," APDA-193, March 15 - June 15, 1966.

6. "Quarterly Technical Progress Report on AEC-Sponsored Activities," APDA-195, June 15 - September 15, 1966.

7. "Quarterly Technical Progress Report on AEC-Sponsored Activities," APDA-197, September 15 - December 15, 1966. 


\section{ACKNOW LEDGEMENTS}

The authors are indebted to Bernie Cerutti (Argonne National Laboratory - EBR-II), H. Douglas Lenkersdorfer (Battelle Northwest Laboratories - FFTF Project), and Ken Foster (Atomics International) who arranged for the participation of other knowledgeable persons at their respective laboratories, as well as to several employes of Atomic Power Development Associates for valuable suggestions for the potential applications of the undersodium ultrasonic scanning device in sodium-cooled reactors. 
No. of Copies

USAEC - Chicago Operations Office

2

Director, Contracts Office

1 G. H. Lee

1 R. J. Gariboldi

USAEC - Washington

N. Grossman

$\mathrm{R}$. H. Jones

W. R. Kornack

J. A. Lieberman

J. J. Morabito

J. M. Simmons

S. A. Szawlewicz

G. W. Wensch

M. Whitman

D. J. Wille

USAEC - DTIE

3

R. L. Shannon

USAEC - New York Operations Office

1 J. Dissler

1 J. Wise

USAEC - San Francisco Operations Office

1 J. Holliday

USAEC - Canoga Park Area Office

2

W. G. Armstrong

USAEC - MCRP, Indianapolis

1 S. Meyers 
No. of Copies

Argonne National Laboratory

$1 \quad$ R. Bane

1 S. Greenberg

1 L. Kelman

1 L. J. Koch

$1 \quad$ K. Kuczen

1 S. Lawroski

I R. E. Macherey

$1 \quad$ M. Novick

1 W. R. Simmons

$1 \quad$ F. Smith

Brookhaven National Laboratory

1 O. E. Dwyer

2 D. Gurinsky

1 K. Hoffman

1 C. Klamut

1 L. Newman

1 A. Romano

Los Alamos Scientific Laboratory

2 D. B. Hall

1 G. Waterbury

1 L. E. Whinery

1 W. R. Wykoff

LMFBR - Argonne National Laboratory

A. Amorosi

Oak Ridge National Laboratory

2 F. L. Culler

1 J. H. Devan

1 D. Gardiner

1 R. E. MacPherson

I J. White

Pacific Northwest Laboratory, BMI

5 E. Astley

1 S. L. Fawcett 
No. of Copies

NASA, Lewis Flight Propulsion Laboratory

1

C. A. Barrett

Aerojet - General Corporation

1

R. S. Carey

Allis-Chalmers Mfg. Co. (Bethesda, Md.)

1 W. S. Farmer

1 L. E. Phillips

1 Library

Atomics International

1 D. T. Eggen

2 D. C. Fulton

1 Liquid Metals Information Center

Babcock \& Wilcox Company

1

P. B. Probert

Baldwin-Lima-Hamilton Corporation

1 J. G. Gaydos

1 R. A. Tidball

Combustion Engineering, Inc.

1

W. H. Zinn

General Atomics, Div. of General Dynamics

1

P. Fortescue

General Electric Company

$3 \mathrm{~K}$. Cohen

M. W. Kellogg Company

1 E. W. Jesser

MSA Research Corporation

1 C. H. Staub 
No. of Copies

Nuclear Materials \& Equipment Corporation

1

Z. M. Shapiro

Power Reactor Development Company

1

A. S. Griswold

Southwest Atomic Energy Associates

1

J. R. Welsh

United Nuclear Corporation

2

A. Strausser

Westinghouse Corporation

2

J. Wright

US-EURA TOM Exchange

10 A. DeStordeur, Brussels

10 W. Haefele, Karlsruhe

4 F. Pierantoni, CNEN, Bologna

10 G. Vendryes, CEN Saclay

US-UKAEA Exchange

12 R. Nicholson

Total 135

September 8, 1966 